\title{
RESEARCH
}

\section{In vitro development of mechanically and enzymatically isolated cat ovarian follicles}

\author{
Jennifer B Nagashima, Andrea M Hill and Nucharin Songsasen
}

Center for Species Survival, Smithsonian Conservation Biology Institute, National Zoological Park, Front Royal, Virginia, USA

Correspondence should be addressed to J B Nagashima: nagashimaj@si.edu

\section{Graphical Abstract}

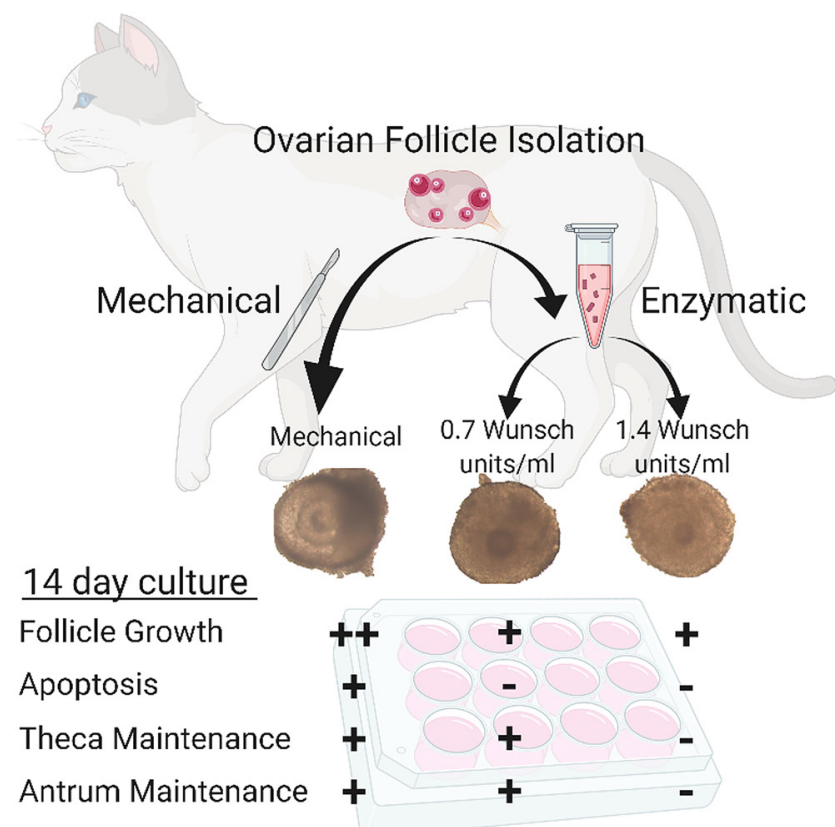

\begin{abstract}
Isolation of ovarian follicles is a key step in culture systems for large mammalian species to promote the continued growth of follicles beyond the preantral stage in fertility preservation efforts. Still, mechanical isolation methods are user-skill dependent and time-consuming, whereas enzymatic strategies carry increased risk of damaging theca cell layers and the basement membranes. Here, we sought to determine an optimal method to rescue domestic cat (Felis catus) early antral and antral stage follicles from ovarian tissue and to evaluate the influence of isolation strategy on follicle development, survival, and gene expression during 14 days of in vitro culture in alginate hydrogel. Mechanical isolation was compared with 90 min digestion in 0.7 and 1.4 Wünsch units $/ \mathrm{mL}$ Liberase blendzyme (0.7L and 1.4L, respectively). Mechanical isolation resulted in improved follicle growth and survival, and better antral cavity and theca cell maintenance in vitro,
\end{abstract}

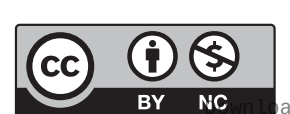
License. 
compared with 1.4L $(P<0.05)$ but displayed higher levels of apoptosis after incubation compared with enzymatically isolated follicles. However, differences in follicle growth and survival were not apparent until 7+ days in vitro. Expressions of CYP19A1, GDF9, LHR, or VEGFA were similar among isolation-strategies. Cultured follicles from all isolation methods displayed reduced STAR expression compared with freshly isolated follicles obtained mechanically or via $0.7 L$, suggesting that prolonged culture resulted in loss of theca cell presence and/or function. In sum, early antral and antral stage follicle development in vitro is significantly influenced by isolation strategy but not necessarily observable in the absence of extended culture. These results indicate that additional care must be taken in follicle isolation optimizations for genome rescue and fertility preservation efforts.

\section{Lay summary}

The ovary contains hundreds of eggs with only a select few developing from an immature stage through to ovulation over the course of an animal's lifetime. Rescue of eggs from this pool, and the ability to grow them in culture to a mature stage, would be incredibly valuable for fertility preservation efforts in both humans and endangered species. Currently, the isolation of ovarian follicles (eggs with their surrounding helper cells) is a key step in culture systems for large mammalian species, to promote continued growth. Yet, isolation methods may affect the follicle's future developmental capacity. We evaluated two isolation strategies, mechanical micro-dissection (needle/scalpel blade) and enzymatic digestion (using Liberase blendzyme) on ovaries of domestic cats obtained via routine spay procedures. Mechanically isolated follicles displayed improved growth, survival, and indications of developmental competence in 14-day culture, compared with high concentration (1.4 Wünsch units $/ \mathrm{mL}$ ) enzyme-isolated follicles. However, mechanical isolation was not different from low ( 0.7 Wünsch units $/ \mathrm{mL}$ ) enzyme for these metrics, or for expression of key genes indicative of follicular cell functions. Further, differences in follicle growth/survival were not apparent until 7+ days in culture. Thus, ovarian follicle isolation strategies influence developmental potential in culture, and extended culture will be required to identify optimal methods for fertility preservation efforts.

Key Words: - Felis catus $\quad$ ovarian follicle $\quad$ antrum $\quad$ theca cell $\quad$ in vitro culture $\quad$ liberase blendzyme

\section{Introduction}

The ovarian follicle is a complex unit consisting of vascularized theca cell layers, a basement membrane or basal lamina, and granulosa cells surrounding a centralized oocyte. Supporting the development and functionality of these cell types over prolonged culture to produce a competent oocyte is the goal of in vitro folliculogenesis systems. Such an in vitro system would be invaluable to both human fertility preservation, and endangered mammal genome rescue efforts (Comizzoli et al. 2010, Smitz et al. 2010). However, supporting folliculogenesis in vitro is particularly challenging in large mammalian species with prolonged folliculogenesis and large preovulatory follicle sizes. Thus far, follicles are typically isolated from ovarian tissues at the preantral/early antral stage to promote further growth in vitro. For example, a multi-step culture method starting with ovarian tissue culture followed by isolated follicle culture was recently utilized to produce metaphase II oocytes from human follicles (McLaughlin et al. 2018). As increased follicle size has been shown to improve oocyte developmental competence in a variety of species (Bagg et al. 2004, Songsasen \& Wildt 2005, Han et al. 2006, Rosen et al. 2008), the ability to isolate functional follicular units from surrounding tissue is key. Yet, methods to perform follicle isolation carry the risk of damaging the follicular unit, particularly theca cells, their precursors, and the follicle's basement membrane, which in turn adversely affects normal hormonal function of the follicle and its future developmental capacity (Young \& McNeilly 2010).

Two methods are primarily utilized to isolate ovarian follicles from surrounding tissue. First is mechanical isolation, either via micro-dissection from the cortical tissue or by pressing samples through cell-dissociating sieves (Jewgenow \& Göritz 1995, Nagashima et al. 2019). In the cat, the latter method has been utilized for the recovery of preantral stage follicles (Jewgenow \& Göritz 
1995) but the primary disadvantage of the sieve technique is that later-stage follicles are too large to pass through the mesh intact. Micro-dissection involves the isolation of individual follicles from surrounding tissue using needles and/or scalpel blades. This method allows for the isolation of early antral and antral stages but is a time-consuming and labor intensive process, which is highly dependent on the skill of the user. Nevertheless, this method has also been utilized for the isolation of antral stage $(0.5-2 \mathrm{~mm}$ diameter) domestic cat ovarian follicles (Rojo et al. 2015) as well as preantral follicles from human (McLaughlin et al. 2018) and domestic dog (Nagashima et al. 2019) ovarian cortices.

The second method for follicle isolation is by enzymatic digestion of the surrounding cortical tissue. Enzymatic isolation of ovarian follicles has been performed in several species, including the mouse (Eppig \& Schroeder 1989), hamster (Roy \& Greenwald 1985), pig (Hirao et al. 1994, Fattahi et al. 2020), cow (Figueiredo et al. 1993), dog (Durrant et al. 1998, Nagashima et al. 2017), and human (Roy \& Treacy 1993, Lierman et al. 2015). A significant disadvantage of this method is that proteolytic enzymes such as collagenase or DNase have damaging effects on the basement membrane and theca layers of the developing follicles (Demeestere et al. 2002). Enzymes typically used for isolation include collagenase alone (types I, IV, or crude) or a blend of collagenase I and DNase. These traditional collagenase preparations can contain variable endotoxin levels, which have been proposed to have detrimental influences on the structural integrity of isolated follicles (Fattahi et al. 2020). The use of Liberase, a purified enzyme blend, has been investigated and compared with collagenase type IA for the isolation of human primordial and primary follicles (Dolmans et al. 2006) in which Liberase-isolated follicles displayed superior morphology compared with those isolated with collagenase. Evaluation of a variety of enzymatic isolation protocols on human follicle quality at different stages of maturation found that Liberase had fewer damaging effects on the structural integrity of the follicle than collagenase (Lierman et al. 2015).

While these previously published studies assess follicle quality immediately after isolation and after 7 and 10 days in vitro (Dolmans et al. 2006, Vanacker et al. 2011, Lierman et al. 2015, Fattahi et al. 2020), they are limited to the evaluation of preantral stage follicles and rarely specifically evaluate the effects of isolation strategy in longer-term culture. Specifically, we were interested in identifying ovarian follicle isolation strategies that allow for the maintenance of theca cell function during longer-term culture and in a non-rodent mammalian model. For this, we utilized the domestic cat (Felis catus), which serves as an excellent model for both human and endangered felid physiology (Menotti-Raymond \& O'Brien 2008, Rojo et al. 2015). The first objective of this study was to optimize an enzymatic isolation protocol by which early antral and antral stage domestic cat follicles can be recovered with minimal damage to the basement membrane and theca cell layers. The second objective was to examine the influence of enzymatic digestion vs mechanical isolation on follicle survival, growth, antral cavity development, and the expression of genes that are indicative of follicular cell functions.

\section{Materials and methods}

All chemicals were purchased from Sigma-Aldrich unless otherwise stated.

\section{Source of ovaries}

Ovaries were obtained by routine ovariohysterectomy performed at local veterinary clinics and transported to the laboratory in L-15 medium containing $30 \mu \mathrm{g} / \mathrm{mL}$ penicillin $G$ and streptomycin sulfate, and $8.8 \mu \mathrm{g} / \mathrm{mL}$ ascorbic acid on ice. Tissues were processed within $6 \mathrm{~h}$ of excision. Slices of cortical tissue were dissected from the surface of each ovary and cut into $2 \mathrm{~mm}^{2}$ pieces. All the recovered tissue from each cat was then divided evenly among treatment groups for follicle isolation.

\section{Ovarian follicle isolation}

Follicles were isolated either via enzymatic digestion with Liberase blendzyme or mechanically. All isolation methods were carried out in a 'Base medium', consisting of minimum essential medium (MEM) supplemented with $2 \mathrm{mM}$ L-glutamine, $50 \mathrm{U} / \mathrm{mL}$ penicillin $\mathrm{G}, 50 \mu \mathrm{g} / \mathrm{mL}$ streptomycin sulfate, $0.1 \mathrm{mg} / \mathrm{mL}$ ascorbic acid, and $3 \mathrm{mg} / \mathrm{mL}$ BSA. Liberase TM (medium thermolysin concentration) was used at 0.7 Wünsch units/mL $(0.7 \mathrm{~L})$ (previously utilized for domestic dog ovarian follicle isolation (Nagashima et al. 2017) and equivalent to 0.135 $\mathrm{mg} / \mathrm{mL}$ ) and 1.4 Wünsch units/mL (1.4L). The Liberase TM enzyme blend contains the neutral protease thermolysin, which disrupts the extracellular matrix of the tissue and it has been shown to maintain normal morphology in isolated ovarian follicles better than collagenase (Dolmans et al. 2006, Lierman et al. 2015). Ovarian tissue 
fragments $\left(2 \mathrm{~mm}^{2}\right)$ were digested at $38^{\circ} \mathrm{C}$ for 60,90 , or 120 min (60 and 120 min only in preliminary study) along with tissue disruption by vortexing (5 s) at low speed every 15 mins. The reaction was discontinued by the 1:1 addition of base medium with $20 \%$ fetal bovine serum (FBS) and transferred to a petri dish for the collection of isolated follicles. The digested tissue was teased apart with needles to achieve complete isolation of the follicles after which follicles were collected via WireTrol (Drummond Scientific Co., Broomall, PA) and transferred to a fresh warm base medium until encapsulation. For mechanical isolation (Mech), follicles were isolated from the surrounding cortical tissue by using a scalpel and a 20-gauge needle under a stereomicroscope. Follicles were then also transferred via WireTrol to a fresh warm base medium until encapsulation. A randomly selected subset $(n=3-5)$ of freshly isolated follicles from each treatment group were preserved in $200 \mu \mathrm{L}$ of RNAlater stabilization solution (Fisher Scientific, Waltham, MA) at $4^{\circ} \mathrm{C}$ for $1 \mathrm{~h}$ and then stored at $-20^{\circ} \mathrm{C}$ for subsequent gene expression evaluation via RT-PCR.

\section{Encapsulation and incubation of isolated follicles}

A $0.3 \%$ alginate hydrogel (Pronova sodium alginate, Novamatrix) was prepared by dissolving the alginate in warm PBS without calcium or magnesium. Follicles were briefly washed in the alginate solution, then drawn up in $4 \mu \mathrm{L}$ alginate and pipetted into a $140 \mathrm{mM} \mathrm{NaCl}, 50 \mathrm{mM}$ $\mathrm{CaCl}_{2}$ solution (1 $\mathrm{mL}$ in a Nunc 4-well dish) and allowed to crosslink for 2 mins before being transferred to a fresh base medium (Xu et al. 2009). Follicles were incubated in $100 \mu \mathrm{L}$ of 'culture medium' consisting of base medium with $0.42 \mu \mathrm{g} / \mathrm{mL}$ insulin, $0.38 \mu \mathrm{g} / \mathrm{mL}$ transferrin, and 0.5 $\mathrm{ng} / \mathrm{mL}$ selenium, and supplemented with $1 \mu \mathrm{g} / \mathrm{mL} \mathrm{FSH}$ and $100 \mathrm{ng} / \mathrm{mL}$ EGF in $5 \% \mathrm{CO}_{2}$ in air at $38.5^{\circ} \mathrm{C}$. Every $48 \mathrm{~h}, 40 \mu \mathrm{L}$ of the incubation medium was manually exchanged with fresh medium.

Using a Leitz DM-IL inverted microscope (Research Instrument, Falmouth, Cornwall, UK) with a heated stage and equipped with a Nikon D5500 camera, follicles were imaged on days 1 (Day $0=$ onset of culture) and 4 (Study \#1) as well as days 7 and 14 (Study \#2). Follicle diameters were measured using ImageJ image processing software (US National Institutes of Health, Bethesda, MD). To account for varying follicle shapes (e.g. oblong), two measurements of each follicle were made at the onset and end of the incubation, including the widest length, and the diameter perpendicular to it. The average of these two measurements was calculated for each follicle and reported as diameter. Diameter assessments made at the onset of culture were used to determine follicle stage with preantral stage follicles at $\leq 205 \mu \mathrm{m}$ (excluded in the current study), early antral follicles $>205$ to $\leq 340 \mu \mathrm{m}$, and antral stage follicles $>340 \mu \mathrm{m}$ diameter (Reynaud et al. 2009).

\section{Liberase blendzyme optimization}

Ovaries from four cats (aged 3-9 months) were used to identify the optimal digestion incubation period for subsequent experiments. Ovarian cortical tissue from individual cats was divided evenly among $0.7 \mathrm{~L}$ and 1.4L digestion protocols for 60,90 , or $120 \mathrm{~min}$ in a $2 \times 3$ design). Post-digestion, follicles displaying good morphology (apparently intact basement membrane and homogenously dark centralized oocyte, $n$ total $=197$ ) were counted.

\section{Isolated follicle culture}

Ovaries from ten cats (aged 6-14 months) were used to evaluate the effects of Liberase TM vs mechanical isolation via micro-dissection on follicle quality and viability in long-term in vitro culture. A 90-min digestion period was selected for enzymatic follicle isolation based on results from preliminary experimentation. A total of 339 follicles (including preantral stage, which were subsequently excluded from culture to focus on stages with developed theca layers) were collected. Early antral $\left(n_{\text {Mech }}=10, n_{0.7 \mathrm{~L}}=41, n_{1.4 \mathrm{~L}}=41\right)$ and antral stage $\left(n_{\text {Mech }}=49\right.$, $n_{0.7 \mathrm{~L}}=78, n_{1.4 \mathrm{~L}}=85$ ) follicles were encapsulated in $0.3 \%$ alginate and cultured individually in a 96-well plate with $100 \mu \mathrm{L}$ culture medium in $5 \% \mathrm{CO}_{2}$ in air at $38.5^{\circ} \mathrm{C}$ for 14 days. Every $48 \mathrm{~h}, 40 \mu \mathrm{L}$ of culture medium from each well was manually exchanged with fresh medium. Diameter evaluations were made on days 1, 3, 7, and 14 at which point damage to basement membranes (granulosa cell or oocyte extrusion) was also evaluated. On day 14 , intact follicles (combining early antral and antral stages) were removed from alginate beads using two 20-gauge needles, and preserved together by isolation group in 200 $\mu \mathrm{L}$ of RNAlater stabilization solution as earlier described for subsequent gene expression evaluation via RT-PCR ( $n=20-39$ follicles/treatment, two to three replicates per treatment). For follicle morphology and apoptosis evaluations (below), follicles from an additional four cats, aged 2-12 months (EA: $n_{\text {Mech }}=5, n_{0.7 \mathrm{~L}}=6$, and $n_{1.4 \mathrm{~L}}=6$; Antral: $n_{\text {Mech }}=15, n_{0.7 \mathrm{~L}}=13$, and $n_{1.4 \mathrm{~L}}=8$ ) were isolated, encapsulated, and cultured for 14 days. At the end of

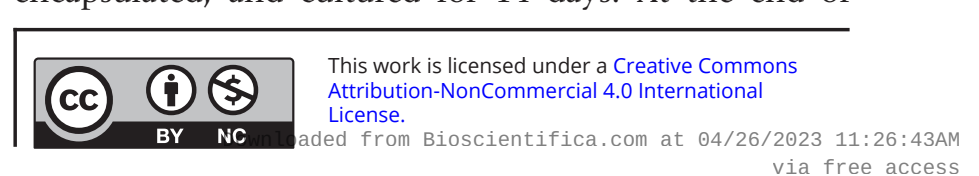


in vitro incubation, surviving and intact follicles were grouped by treatment and individual animals and fixed in $4 \%$ PFA until histological evaluation.

\section{Histological evaluations}

Alginate-encapsulated, fixed cultured follicles $\left(n_{\text {Mech }}=19\right.$, $n_{0.7 \mathrm{~L}}=16$, and $n_{1.4 \mathrm{~L}}=13$ ) were embedded in paraffin, cut into $6 \mu \mathrm{m}$ thick sections and mounted on glass slides. For morphological analyses, on average, a total of 13 sections representing approximately $300 \mu \mathrm{m}$ depth were processed for hematoxylin and eosin $(\mathrm{H}+\mathrm{E})$ staining, as previously described (Nagashima et al. 2019), for each follicle and treatment groups. This was achieved by evaluating the first eight sections (i.e. $48 \mu \mathrm{m}$ depth) and then two sections of every ten subsequent slices. Following $\mathrm{H}+\mathrm{E}$ staining, slides were assessed under light microscopy (Olympus $\mathrm{B} \times 40$ ) for antral cavity status and putative theca cell layer presence. In $\mathrm{H}+\mathrm{E}$ stained sections containing follicular oocytes with visible nucleoli, oocyte diameter was measured by averaging measurements of the oocyte at its widest diameter and its perpendicular diameter.

For apoptosis evaluation, two sections of every ten slices (also cumulatively representing $\sim 300 \mu \mathrm{m}$ depth) were assessed for indirect terminal deoxynucleotidy transferase dUTP nick end label using ApopTag Fluorescein In Situ Apoptosis Detection Kit (Sigma-Aldrich S7110), as per manufacturer's instructions. Positive control slides were incubated with DNase for $15 \mathrm{~min}$ at $37^{\circ} \mathrm{C}$ following deparaffinization and rehydration, and negative controls were incubated in PBS in lieu of anti-digoxigenin antibody. All slides were counterstained with $1 \mu \mathrm{g} / \mathrm{mL}$ DAPI (Invitrogen S33025) in Prolong Anti-fade mountant (Thermo Fisher P36980) and imaged under fluorescent microscopy (EVOS FL Auto 2, Thermo Fisher). Area of ApopTag- positive staining was normalized to area of DAPI-positive staining per image (as a proxy quantitation for proportion of TUNEL-positive cells) in ImageJ ( $\mathrm{v}$ $1.52 p$, from imagej.nih.gov/ij). For each cat $(n=4$ individuals), 3-6 follicles were evaluated per treatment group, with the exception of one cat for which only one 1.4L follicle survived until day 14 . Results are reported as average \pm S.E.M. across individual cats for each treatment group.

\section{RNA isolation and RT-PCR}

Freshly isolated and post-14 days cultured follicles were grouped together according to isolation method and culture status and RNA extracted via RNeasy Plus Mini Kit (Qiagen), according to the manufacturer's protocol followed by treatment with RapidOut DNA removal kit (Thermo-Scientific) to eliminate genomic DNA contamination. Total extracted RNA was quantified using a NanoDrop ${ }^{\mathrm{TM}}$ One/OneC Microvolume UV-Vis Spectrophotometer (Thermo-Scientific).

cDNA was synthesized from 100 ng mRNA using a Transcriptor High Fidelity cDNA synthesis kit (Roche), according to the manufacturer's instructions. Expression of the following genes was evaluated: $\beta$-actin ((Thongkittidilok et al. 2018), a reference gene), aromatase (CYP19A1 (Thongkittidilok et al. 2018), a measure of steroidogenesis in granulosa cells), growth differentiation factor 9 (GDF9 (Chansaenroj et al. 2019), oocyte-derived factor necessary for theca cell layer development (Dong et al. 1996)), luteinizing hormone receptor (LHR, a marker for theca cell function), STAR protein ( (Thongkittidilok et al. 2018) a regulator of cholesterol transfer for theca cell steroidogenesis), and vascular endothelial growth factor (VEGFA, a potential marker of theca cell presence and functionality). Primer details are included in Table 1. Reactions were performed according to the following parameters: $95^{\circ} \mathrm{C}$ for $10 \mathrm{~min}$ preincubation, followed by 50 cycles amplification at $95^{\circ} \mathrm{C} 30 \mathrm{~s}, 60^{\circ} \mathrm{C}$ for $10 \mathrm{~s}, 72^{\circ} \mathrm{C}$ for $10 \mathrm{~s}$, and melting at $95^{\circ} \mathrm{C}$ for $10 \mathrm{~s}, 65^{\circ} \mathrm{C}$ for $1 \mathrm{~min}$, and $97^{\circ} \mathrm{C}$ for $1 \mathrm{~s}$. All reactions were performed in duplicate using a LightCycler® 96 (Roche). Primer efficiency was assessed for each gene by serially diluting cDNA and used for analysis via the Pfaffl method (Pfaffl 2001).

Table 1 Primer details.

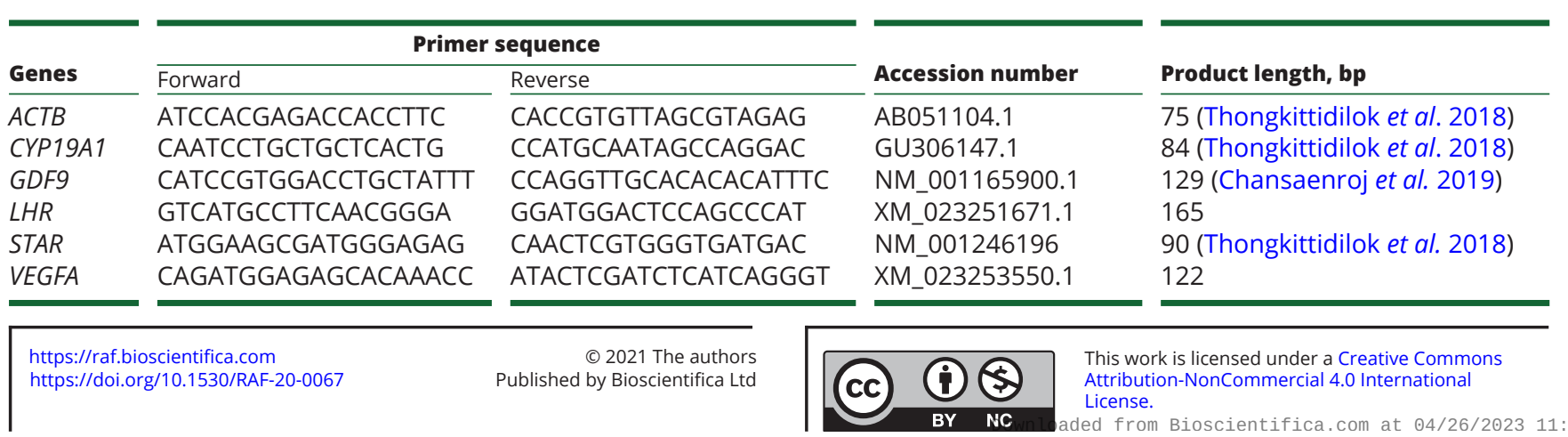



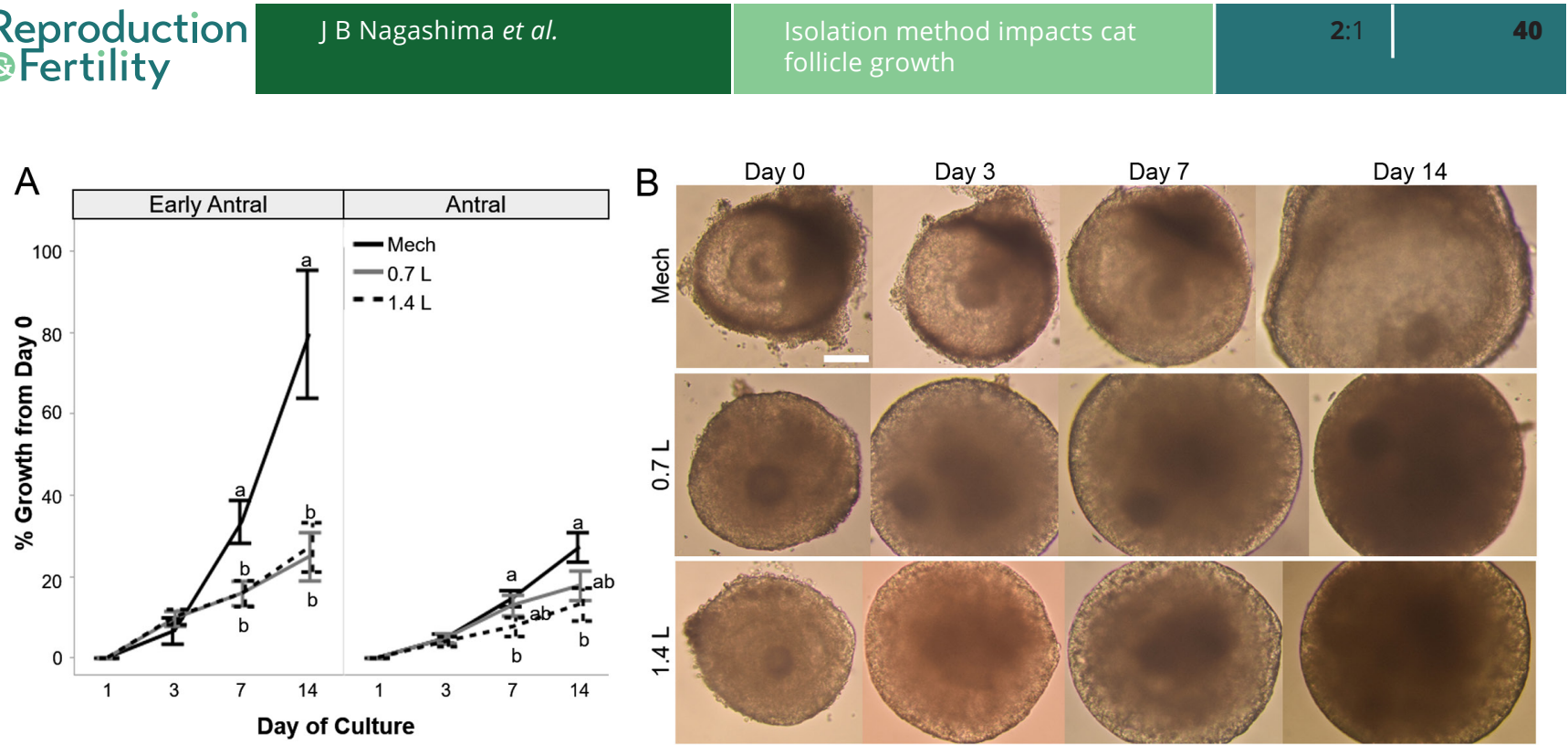

Figure 1 Growth over 14 days alginate-encapsulated in vitro culture of $(\mathrm{A})$ early antral and antral stage follicles isolated mechanically or via $0.7 \mathrm{~L}$ or $1.4 \mathrm{~L}$ digestion, with letters indicating differences among isolation groups for each stage on a given day of culture $(P<0.05)$, and $(B)$ representative images of size-matched follicles isolated via the three methods. White bar $=100 \mu \mathrm{m}$.

\section{Statistical evaluations}

Data analyses were performed with JMP Pro 12 software (SAS Institute Inc., Cary, NC, USA). Follicle growth was evaluated via standard least squares with the day of culture, isolation technique and follicle stage as well as the interaction between isolation technique and stage, as fixed effects, and individual cat as a random variable. Post hoc evaluations of growth on each day of culture were performed via Wilcoxon non-parametric test with significance set at $P<0.05$. Evaluations of basement membrane integrity, antral cavity status, putative theca cell presence, and TUNEL staining between treatment groups after culturing for 14 days were also performed via Wilcoxon non-parametric test. Survival over the culture period was evaluated with Cox proportional hazards test with isolation strategy and follicle size and their interactions.

\section{Results}

In the preliminary evaluation of enzymatic digestion time $(60,90$, vs $120 \mathrm{~min})$ with both 0.7 and 1.4 Wünsch units/mL of Liberase blendzyme, more differences were observed between individual cats than between treatment groups in terms of follicle yield (Supplementary Fig. 1 , see section on supplementary materials given at the end of this article). Thus, a digestion period of $90 \mathrm{~min}$ was selected to promote the isolation of early antral and antral stage follicles while allowing sufficient time for mechanical follicle isolation to be completed in parallel.
Subsequently, 0.7 and 1.4 Wünsch units/mL Liberase blendzyme were compared with mechanical dissection. Both early antral and antral stage follicles isolated via mechanical dissection experienced significantly higher growth than the enzymatically isolated counterparts, an effect that reached statistical significance in the latter half of culture (Fig. 1A). There was no difference between enzyme concentrations. For example, mechanically isolated early antral stage follicles increased in diameter $79.6 \pm 15.7 \%$ (mean \pm S.E.M., from an average $290.5 \pm 12.4$ $\mu \mathrm{m}$ initial diameter to $513.5 \pm 52.1 \mu \mathrm{m}$ final diameter) by day 14, compared with $24.9 \pm 5.9 \%$ (282.5 \pm 5.8 to $343.8 \pm 22.0 \mu \mathrm{m})$ and $27.2 \pm 6.0 \%(284.9 \pm 5.5$ to $369.1 \pm 20.7 \mu \mathrm{m})$ for $0.7 \mathrm{~L}$ and $1.4 \mathrm{~L}$-isolated follicles, respectively $(P<0.05)$. Similarly, Mech-isolated antral follicles experienced a change in diameter of $27.2 \pm 3.6 \%$ $(438.9 \pm 8.7$ to $613.6 \pm 17.7 \mu \mathrm{m})$ compared with $17.8 \pm 3.6$ $(420.5 \pm 6.0$ to $499.2 \pm 11.7 \mu \mathrm{m})$ for $0.7 \mathrm{~L}$ follicles and $13.2 \pm 4.0 \%(419.2 \pm 6.5$ to $481.1 \pm 17.4 \mu \mathrm{m})$ for $1.4 \mathrm{~L}$ follicles $(P<0.05)$. It should be noted that while 'excess' stromal cells were present on most follicles at the onset of culture, more were co-isolated with mechanical dissection compared with enzymatic methods (Fig. 1B).

A loss of basement membrane integrity in 40-60\% of enzymatically isolated follicles was observable over the course of in vitro culture (Fig. 2A). While the loss of basement membrane integrity also occurred in mechanically isolated follicles, rates were significantly reduced for antral stage follicles. As a result, mechanically isolated antral follicles experienced significantly improved survival rates over 2 -week culture ( $P<0.05$, Fig. $2 \mathrm{~B})$. 
A

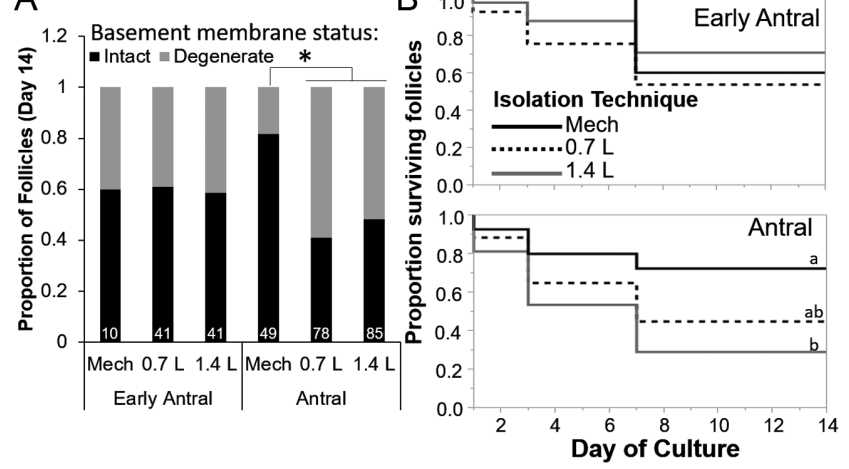

Figure 2 Early antral and antral stage domestic cat follicle survival in vitro after Mech isolation compared with $0.7 \mathrm{~L}$ and $1.4 \mathrm{~L}$ with (A) proportion of intact basement membranes on day 14 of culture, with asterisk (*) indicating differences among isolation groups for each stage and total follicles per group in white text, and (B) Kaplan-Meier survival, with letters indicating differences among isolation groups for each stage. $P<0.05$.

In histological evaluations, a large portion of mechanically isolated follicles demonstrated antral cavities $(63.8 \pm 9.0 \%)$ and presence of cells with theca-like morphology $(65.0 \pm 12.6 \%)$. In contrast, follicles isolated via enzymatic digestion in $1.4 \mathrm{~L}$ displayed the reduced presence of these characteristics $(P<0.05$, Fig. 3$)-$ with follicles from only one cat maintaining either following culture. While $\mathrm{H}+\mathrm{E}$ sections containing oocyte nucleoli were only identified in 20 follicles, and the measured values at nucleoli-containing slices did not necessarily represent the largest diameters, only one oocyte with a pyknotic nucleus was observed and average diameters were $77.7 \pm 3.6,77.8 \pm 4.8$, and $85.2 \pm 5.5 \mu \mathrm{m}$ for $0.7 \mathrm{~L}$, $1.4 \mathrm{~L}$, and Mech follicles, respectively $(P>0.05)$. IndirectTUNEL staining of follicles following in vitro culture (Fig. 4A, controls in Supplementary Fig. 2) revealed a higher proportion of cells in Mech-isolated follicles with positive signal (normalized to DAPI, Fig. 4B). Apoptotic cells were observed at low levels, primarily in the granulosa cell layer in all treatment groups (Fig. 4A). Mech and 0.7L-isolated follicles also displayed evidence of apoptosis in theca cell layers (Fig. 4A and C).

Early antral and small antral follicles were pooled for gene expression evaluations. Fresh follicles collected immediately following isolation in either Mech, $0.7 \mathrm{~L}$, or $1.4 \mathrm{~L}$ were compared with follicles isolated with each method and subsequently cultured for 14 days. Gene expression results were compared with fresh, mechanically isolated follicles. No significant differences in expression were observed among treatment groups for CYP19A, GDF9, LHR, or VEGFA (Fig.5). Cultured follicles, regardless of isolation strategy, displayed reduced STAR expression compared with fresh/uncultured Mech- and

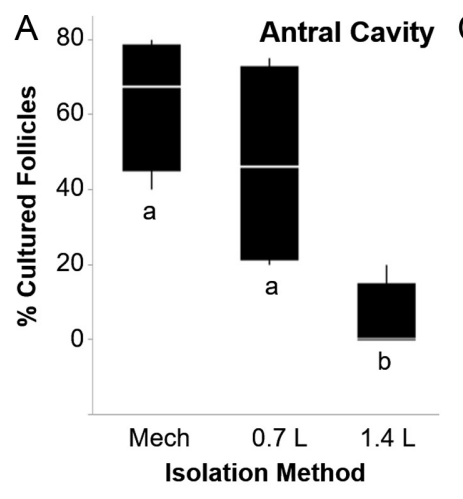

B

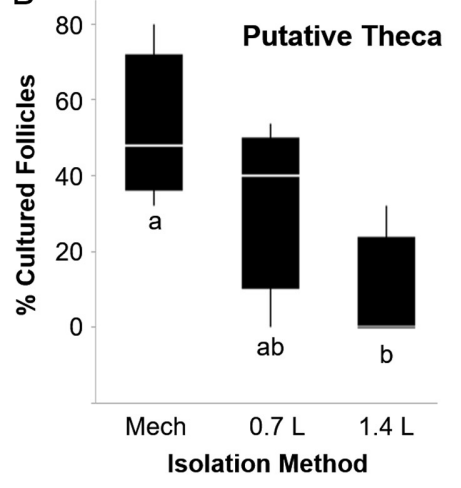

Isolation Method
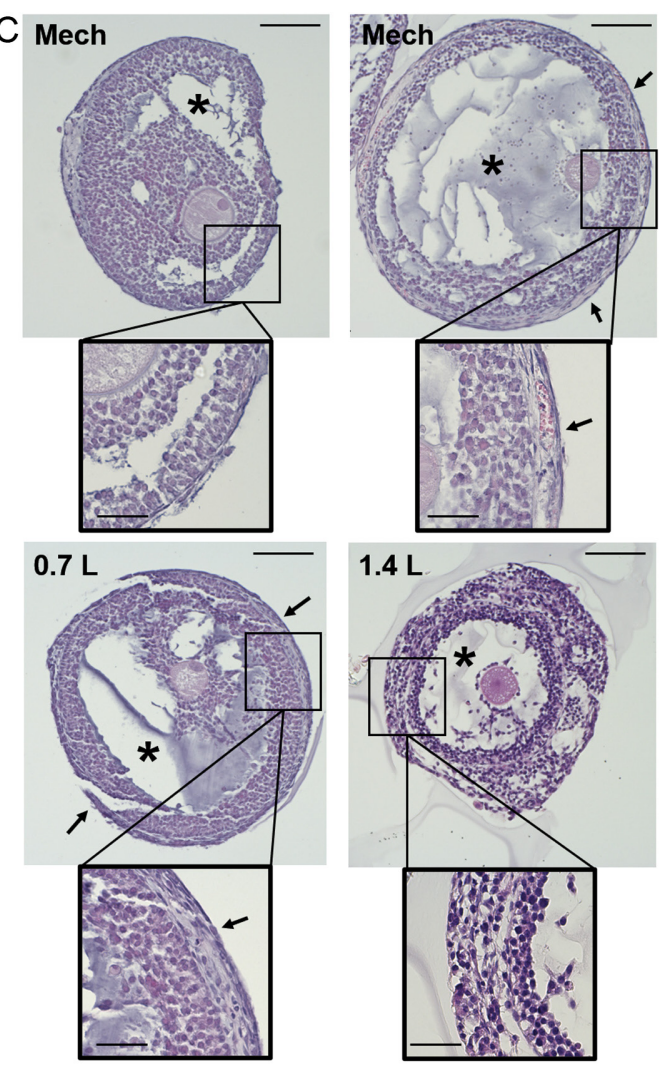

Figure 3 Cat follicles with antral cavities and/or putative theca cell layers after 14 days of in vitro culture, with percent of follicles (Mech, $n=19$; $0.7 \mathrm{~L}, n=16$, and 1.4L $n=13$ ) displaying (A) antral cavities, or (B) putative theca cell layers, with letters indicating differences among isolation methods $(P<0.05)$, and $(C)$ representative $\mathrm{H}+\mathrm{E}$ images of Mech- vs $0.7 \mathrm{~L}$ and $1.4 \mathrm{~L}$-isolated follicles, with * denoting antral cavities and black arrows marking putative theca layers. Scale bar $=100 \mu \mathrm{m}$. https://raf.bioscientifica.com https://doi.org/10.1530/RAF-20-0067 (c) 2021 The authors Published by Bioscientifica Ltd
This work is licensed under a Creative Commons Attribution-NonCommercial 4.0 International

License.
ded from Bioscientifica.com at 04/26/2023 11:26:43AM 
A

Brightfield

DAPI

ApopTag

Merged
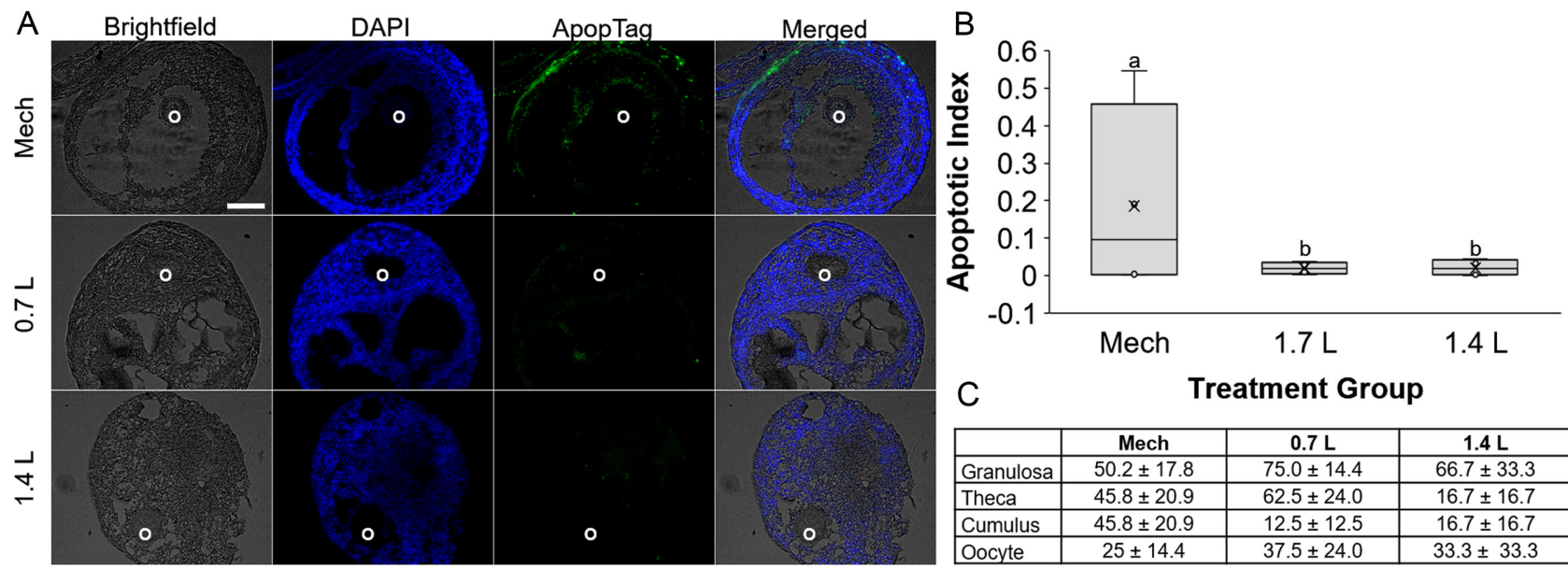

\begin{tabular}{|l|c|c|c|}
\hline & Mech & $\mathbf{0 . 7} \mathbf{L}$ & $\mathbf{1 . 4} \mathbf{L}$ \\
\hline Granulosa & $50.2 \pm 17.8$ & $75.0 \pm 14.4$ & $66.7 \pm 33.3$ \\
\hline Theca & $45.8 \pm 20.9$ & $62.5 \pm 24.0$ & $16.7 \pm 16.7$ \\
\hline Cumulus & $45.8 \pm 20.9$ & $12.5 \pm 12.5$ & $16.7 \pm 16.7$ \\
\hline Oocyte & $25 \pm 14.4$ & $37.5 \pm 24.0$ & $33.3 \pm 33.3$ \\
\hline
\end{tabular}

Figure 4 Apoptosis in domestic cat ovarian follicles isolated mechanically (Mech) or with 0.7 or 1.4 Wünsch units/mL Liberase blendzyme (0.7L, 1.4L) following 14 days in vitro culture with (A) representative brightfield, DAPI (blue), TUNEL (ApopTag, green), and merged images, (B) apoptotic index, where letters indicate statistically significant $(P<0.05)$ differences among treatment groups, and $(C)$ percentage $( \pm$ S.E.M.) of follicles from each treatment group with indirect TUNEL signal in granulosa, theca, or cumulus cells, or the oocyte.

0.7L-isolated controls. Uncultured follicles isolated in 1.4L also displayed reduced STAR expression compared with uncultured, Mech- and 0.7L-isolated controls $(P<0.05)$.

\section{Discussion}

In this study, we evaluated the impact of various isolation strategies for domestic cat early antral and antral stage ovarian follicles on in vitro survival, growth, and gene expression. We found that (1) mechanical isolation resulted in improved follicle growth and survival for early antral and antral stage follicles, respectively, when compared

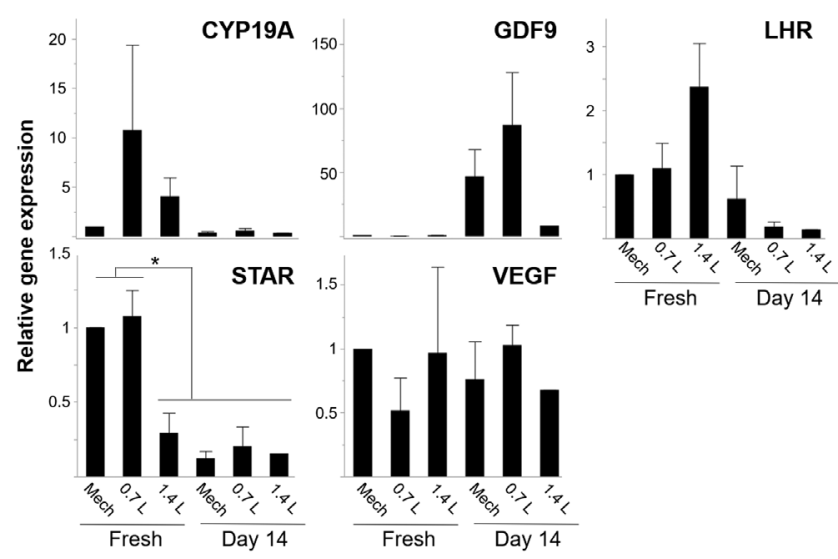

Figure 5 Gene expression relative to fresh, mechanically isolated domestic cat ovarian follicles, normalized to $\beta$-actin after isolation (Fresh), or following 14 day in vitro culture (Day 14) for each isolation method. Asterisk $\left(^{*}\right)$ represents statistically significant differences among groups $(P<0.05)$.

https://raf.bioscientifica.com https://doi.org/10.1530/RAF-20-0067

(c) 2021 The authors Published by Bioscientifica Ltd with enzymatic methods, (2) differences in isolation strategy on in vitro follicle surviaval and development were only observable after $>7$ days culture, and (3) both mechanical and low-concentration enzymatic isolation appear to sustain theca cell layers for subsequent culture.

Previous studies have utilized either mechanical or enzymatic methods to isolate varying stage cat ovarian follicles. Yet, direct comparisons of the efficacy and impact of follicle isolation methods on in vitro growth and survival have been limited. In this study, we compared mechanical dissection vs enzymatic digestion with Liberase blendzyme TM at low (0.7 Wünsch units/mL) or high (1.4 Wünsch units $/ \mathrm{mL}$ ) concentrations. Our observation of the appearance of significant deviations in follicle growth and survival trajectories based on isolation strategy only after 7+ days of culture is notable. Namely, though fewer early antral stage follicles were collected via mechanical dissection compared to enzymatic in the 90 min time frame, Mech-isolated early antral follicles displayed the most robust growth in vitro. While several studies have evaluated various enzymatic isolation techniques for ovarian follicles, to our knowledge the longest culture duration applied to evaluate isolation methodology have been 7 (Vanacker et al. 2011) and 10 days (Fattahi et al. 2020). In the former study, similar protocols were applied to human ovarian biopsies for primordial and primary follicle isolation; however, owing to the stage, follicles were group-cultured, so following the individual fate of follicles over the culture period was not possible. In the latter study, porcine preantral follicles were isolated using mechanical (hand blender or mincing with a scalpel) and enzymatic (collagenase or Liberase DH) methods
This work is licensed under a Creative Commons Attribution-NonCommercial 4.0 International License. 
(Fattahi et al. 2020). Few intact follicles were collected via the mechanical methods utilized in that study, and therefore subsequent cultures were not performed on mechanically isolated follicles. Nevertheless, the authors similarly demonstrated a large disparity in survival following 10 days culture between follicles isolated with the two other strategies - collagenase ( 28\% survival) and Liberase DH ( 58\% survival) (Fattahi et al. 2020). Though these previous studies focused on preantral stage follicles in contrast with the current study, our results emphasize that both survival and growth potential of follicles are impacted by isolation method. These findings emphasize the need for prolonged ( $>7$ days) post-isolation assessment for full evaluation of isolation techniques.

Various Liberase blends, dosages, and exposure times have been applied to the isolation of ovarian follicles in a variety of species (Dolmans et al. 2006, Lierman et al. 2015, Nagashima et al. 2017). For the Liberase TM utilized in the current study, concentrations typically range from 0.2-1.3 Wünsch units $/ \mathrm{mL}$ with incubation periods ranging from 12-80 min (Dolmans et al. 2006, Kristensen et al. 2011, Schmidt et al. 2018, Buckenmeyer et al. 2020) for the isolation of preantral follicles. Specifically, 1.3 Wünsch units $/ \mathrm{mL}$ concentration of Liberase $\mathrm{TM}$ has previously been applied to the isolation of murine primordial follicles over a 12 min incubation period (Buckenmeyer et al. 2020), but for human preantral follicles a range of 0.20-0.25 Wünsch units/mL with 70-80 min incubation is typically utilized (Dolmans et al. 2006, Kristensen et al. 2011, Schmidt et al. 2018). Recently, $0.5 \mathrm{mg} / \mathrm{mL}$ Liberase DH (equivalent to 3 Wünsch units/mL but with lower neutral protease activity than TM) for 70 min was used in the isolation of preantral porcine follicles (Fattahi et al. 2020). Although the 1.4 Wünsch units $/ \mathrm{mL}$ for 90 min condition used in the present study was within the range used in previous research, follicles isolated via $1.4 \mathrm{~L}$ rarely maintained/developed antral cavities during the in vitro incubation. This was likely due to damage to the theca cell layer during isolation, which was indicated in both the histological evaluations and STAR expression level reduction following isolation. However, follicles recovered by incubating ovarian tissue with a lower concentration ( 0.7 Wünsch units $/ \mathrm{mL}$ ) of Liberase grew and sustained the antral cavity and theca-like cells even after 14 days. The findings observed in the present study for the cat were similar to those reported previously by our laboratory with pre- and early- antral stage domestic dog follicles (Nagashima et al. 2017). In that study, 0.7 Wünsch units/mL of Liberase TM supported the isolation of early antral stage follicles with the capacity to grow and produce steroids for at least 14 days in vitro.

The influence of excess co-isolated stromal cells on follicle growth cannot be discounted. These cells were not observed to proliferate disproportionately in vitro (Figs 1B and 3C), so did not contribute directly to the increased percent growth reached by mechanically isolated follicles in culture. Rather, we hypothesize that they supported follicle development. In the mouse, preantral follicles co-cultured with murine fibroblasts had improved survival and growth in 12 days in vitro culture (Kim et al. 2013). Ovarian stromal cells, identified as primarily theca cells and macrophages, also support primary and early secondary murine follicle growth and survival (Tingen et al. 2011). In a large mammalian example, buffalo preantral follicles had better survival and development in ovarian mesenchymal cell co-culture compared with controls, although co-culture with isolated cumulus cells was determined to have the best influence (Ramesh et al. 2008). In these studies, it was suggested that cytokines and growth factors produced by the stromal cells or involved in their communication with the ovarian follicles are likely responsible for the beneficial effects. As such, it is possible that the presence of additional stromal cells, less prevalent in enzymatically isolated follicles, conferred a similar advantage in the current study with the mechanically isolated follicles.

Our finding of higher percentages of TUNEL-positive cells in mechanically vs enzymatically isolated follicles following 14 days culture was surprising. Looking more closely at the localization, over half of the cultured follicles, regardless of treatment group, displayed low levels of indirect-TUNEL staining in granulosa cells. However, as noted by others, the observation of apoptotic granulosa cells in antral follicles can also be a part of the normal developmental process (Van Wezel et al. 1999, Regan et al. 2018). As previously noted, $1.4 \mathrm{~L}$-isolated follicles rarely displayed evidence of theca cell layers or antral cavities after 14 days culture, therefore little to no staining was localized to theca or cumulus cells in that group. In contrast, the relatively high positive signal in Mechisolated follicles after 14 days culture can be attributed to these areas. In the cow, stimulation of theca cells with luteinizing hormone (LH) has been demonstrated to promote insulin-like growth factor expression, which in turn protects granulosa cells from apoptosis and supports follicle survival (Hattori et al. 2018). In our current culture system, we did not supplement LH during incubation. Though chronic LH supplementation in vitro has been

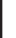

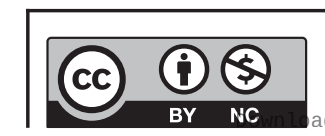


demonstrated to downregulate follicle responsiveness to FSH in the rat (Orisaka et al. 2013), sequential (e.g. added only in the latter half of culture) or intermittent (i.e. timed pulsatile addition) supplementation of LH may better support theca cell presence/function during extended culture in vitro. As oocyte developmental competence improves with advancing follicle size/stages, we propose that additional modifications to the culture system for these early antral and antral stage follicles should be explored for future genome rescue efforts.

It was promising to observe that, overall, gene expression was not significantly impacted by follicle isolation strategy. Based on what is known about the follicular localization of CYP19A1 (primarily granulosa cells (Duggavathi et al. 2006, Echternkamp et al. 2012)), GDF9 (primarily oocyte (Aaltonen et al. 1999, Paradis et al. 2009)) and VEGFA (both theca and granulosa cells (Yamamoto et al. 1997)) in other species, it follows that they were not overly influenced by isolation technique. Conversely, STAR is primarily localized to theca cells in murine and human follicles (Kiriakidou et al. 1996, RonenFuhrmann et al. 1998). Reduced STAR in fresh, 1.4L-isolated follicles compared with Mech and 0.7L further indicates theca cell loss as a result of the more intensive enzymatic isolation strategy. LHR immunolocalizes to theca cells of domestic cat follicles of the early antral stage on but also in granulosa cells of large ( $>800 \mu \mathrm{m}$ diameter) antral follicles and ovarian stromal cells (Saint-Dizier et al. 2007). LH stimulates STAR expression (Clark et al. 1995) and subsequently the production of androgens (Short 1962) to support the steroidogenic activity needed for advancement of folliculogenesis. Thus, the observed lower STAR expression in cultured follicles also supports the need for LH supplementation in the culture of these early antral and antral stage domestic cat follicles mentioned earlier.

In conclusion, we have determined that both mechanical micro-dissection and enzymatic digestion with 0.7 Wünsch units/mL Liberase blendzyme allow for the isolation of developmentally functional, advanced stage domestic cat ovarian follicles. Still, mechanically isolated early antral and antral follicles display improved growth and survival, respectively, during extended in vitro culture, potentially owing to the presence of an intact theca layer and supportive stromal cells. Oocyte morphology and size following culture were comparable to what has been reported for early antral stage cat follicles; however, subsequent studies should also evaluate the developmental competence of oocytes from these cultured follicles. Further, improved long-term culture conditions to maintain theca cell presence and/or steroidogenic activity will be beneficial toward the objective of improving the production of meiotically competent oocytes from isolated domestic cat follicles in vitro.

Research reported in this publication was supported by the Eunice Kennedy Shriver National Institute of Health \& Human development of the National Institutes of Health. The content is solely the responsibility of the authors and does not necessarily represent the official views of the National Institutes of Health.

\section{Supplementary materials}

This is linked to the online version of the paper at https://doi.org/10.1530/ RAF-20-0067.

\section{Declaration of interest}

The authors declare that there is no conflict of interest that could be perceived as prejudicing the impartiality of the research reported.

\section{Funding}

This research was supported by the National Institutes of Health fellowship 5F32HD090854-03 () B N) and by the Smithsonian Institution.

\section{Author contribution statement}

J B N and A M H designed the study and performed the experiments, J B N, $\mathrm{A} \mathrm{M} \mathrm{H}$ and N S analyzed the results and prepared the manuscript.

\section{Acknowledgements}

The authors thank the local veterinary clinics in Front Royal, Stephen's City, Harrisonburg, and Manasses, VA. The authors acknowledge that Biorender.com was used to create the graphical abstract.

\section{References}

Aaltonen J, Laitinen MP, Vuojolainen K, Jaatinen R, HorelliKuitunen N, Seppä L, Louhio H, Tuuri T, Sjöberg J,

Bützow R, et al. 1999 Human growth differentiation factor 9 (GDF-9) and its novel homolog GDF-9B are expressed in oocytes during early folliculogenesis. Journal of Clinical Endocrinology and Metabolism 84 2744-2750. (https://doi.org/10.1210/jcem.84.8.5921)

Bagg MA, Vassena R, Papasso-Brambilla E, Grupen CG, Armstrong DT \& Gandolfi F 2004 Changes in ovarian, follicular, and oocyte morphology immediately after the onset of puberty are not accompanied by an increase in oocyte developmental competence in the pig. Theriogenology 62 1003-1011. (https://doi. org/10.1016/j.theriogenology.2003.12.028) 
Buckenmeyer MJ, Sukhwani M, Iftikhar A, Nolfi AL, Xian Z, Dadi S, Case ZW, Steimer SR, D'Amore A \& Orwig KE 2020 Bioengineering an in situ ovary (ISO) for fertility preservation. bioRxiv. (https://doi.org/10.1101/2020.01.03.893941)

Chansaenroj A, Songsasen N \& Chatdarong K 2019 Equine chorionic gonadotropin induces in vitro follicular growth from the multi-layered secondary developmental stage in cats. Theriogenology 123 116-122. (https://doi.org/10.1016/j.theriogenology.2018.09.040)

Clark BJ, Soo SC, Caron KM, Ikeda Y, Parker KL \& Stocco DM 1995 Hormonal and developmental regulation of the steroidogenic acute regulatory protein. Molecular Endocrinology 9 1346-1355. (https://doi.org/10.1210/mend.9.10.8544843)

Comizzoli P, Songsasen N \& Wildt DE 2010 Protecting and extending fertility options for females of wild and endangered species. Cancer Treatment and Research 156 87-100. (https://doi. org/10.1007/978-1-4419-6518-9_7)

Demeestere I, Delbaere A, Gervy C, Van den Bergh M, Devreker F \& Englert Y 2002 Effect of preantral follicle isolation technique on in vitro follicular growth, oocyte maturation and embryo development in mice. Human Reproduction 17 2152-2159. (https://doi.org/10.1093/humrep/17.8.2152)

Dolmans MM, Michaux N, Camboni A, Martinez-Madrid B, Van Langendonckt A, Annarita Nottola SA \& Donnez J 2006 Evaluation of liberase, a purified enzyme blend, for the isolation of human primordial and primary ovarian follicles. Human Reproduction 21 413-420. (https://doi.org/10.1093/humrep/dei320)

Dong J, Albertini DF, Nishimori K, Kumar TR, Lu N \& Matzuk MM 1996 Growth differentiation factor-9 is required during early ovarian folliculogenesis. Nature 383 531-535. (https:// doi.org/10.1038/383531a0)

Duggavathi R, Janardhan K, Singh J, Singh B, Barrett DMW, Davies KL, Bagu ET \& Rawlings NC 2006 Patterns of expression of steroidogenic enzymes during the first wave of the ovine estrous cycle as compared to the preovulatory follicle. Animal Reproduction Science 91 345-352. (https://doi.org/10.1016/j. anireprosci.2005.05.020)

Durrant BS, Pratt NC, Russ KD \& Bolamba D 1998 Isolation and characterization of canine advanced preantral and early antral follicles. Theriogenology 49 917-932. (https://doi.org/10.1016/s0093691x(98)00041-7)

Echternkamp SE, Aad PY, Eborn DR \& Spicer LJ 2012 Increased abundance of aromatase and follicle stimulating hormone receptor mRNA and decreased insulin-like growth factor-2 receptor mRNA in small ovarian follicles of cattle selected for twin births. Journal of Animal Science 90 2193-2200. (https://doi.org/10.2527/jas.20114735)

Eppig JJ \& Schroeder AC 1989 Capacity of mouse oocytes from preantral follicles to undergo embryogenesis and development to live young after growth, maturation, and fertilization in vitro. Biology of Reproduction 41 268-276. (https://doi.org/10.1095/ biolreprod41.2.268)

Fattahi A, Liverani L, Dittrich R, Hoffmann I, Boccaccini AR, Beckmann MW \& Bleisinger N 2020 Optimization of porcine ovarian follicle isolation methods for better developmental potential. Tissue Engineering: Part A 26 712-719. (https://doi.org/10.1089/ten. tea.2020.0058)

Figueiredo JR, Hulshof SC, Van den Hurk R, Ectors FJ, Fontes RS, Nusgens B, Bevers MM \& Beckers JF 1993 Development of a combined new mechanical and enzymatic method for the isolation of intact preantral follicles from fetal, calf and adult bovine ovaries. Theriogenology 40 789-799. (https://doi. org/10.1016/0093-691x(93)90214-p)

Han ZB, Lan GC, Wu YG, Han D, Feng WG, Wang JZ \& Tan JH 2006 Interactive effects of granulosa cell apoptosis, follicle size, cumulus-oocyte complex morphology, and cumulus expansion on the developmental competence of goat oocytes: a study using the well-in-drop culture system. Reproduction 132 749-758. (https://doi. org/10.1530/REP-06-0055)

Hattori K, Orisaka M, Fukuda S, Tajima K, Yamazaki Y, Mizutani T \& Yoshida Y 2018 Luteinizing hormone facilitates antral follicular maturation and survival via thecal paracrine signaling in cattle. Endocrinology 159 2337-2347. (https://doi. org/10.1210/en.2018-00123)

Hirao Y, Nagai T, Kubo M, Miyano T, Miyake M \& Kato S 1994 In vitro growth and maturation of pig oocytes. Journal of Reproduction and Fertility 100 333-339. (https://doi.org/10.1530/ jrf.0.1000333)

Jewgenow K \& Göritz F 1995 The recovery of preantral follicles from ovaries of domestic cats and their characterisation before and after culture. Animal Reproduction Science 39 285-297. (https://doi. org/10.1016/0378-4320(95)01397-I)

Kim CH, Cheon YP, Lee YJ, Lee KH, Kim SH, Chae HD \& Kang BM 2013 The effect of fibroblast co-culture on in vitro maturation of mouse preantral follicles. Development and Reproduction 17 269-274. (https://doi.org/10.12717/DR.2013.17.3.269)

Kiriakidou M, Mcallister JM, Sugawara T \& Strauss 3rd JF 1996 Expression of steroidogenic acute regulatory protein (StAR) in the human ovary. Journal of Clinical Endocrinology and Metabolism $\mathbf{8 1}$ 4122-4128. (https://doi.org/10.1210/jcem.81.11.8923870)

Kristensen SG, Rasmussen A, Byskov AG \& Andersen CY 2011 Isolation of pre-antral follicles from human ovarian medulla tissue. Human Reproduction 26 157-166. (https://doi.org/10.1093/humrep/ deq318)

Lierman S, Tilleman K, Cornelissen M, De Vos WH, Weyers S, T'Sjoen G, Cuvelier CA \& De Sutter P 2015 Follicles of various maturation stages react differently to enzymatic isolation: a comparison of different isolation protocols. Reproductive Biomedicine Online 30 181-190. (https://doi.org/10.1016/j.rbmo.2014.10.009)

McLaughlin M, Albertini DF, Wallace WHB, Anderson RA \& Telfer EE 2018 Metaphase II oocytes from human unilaminar follicles grown in a multi-step culture system. Molecular Human Reproduction 24 135-142. (https://doi.org/10.1093/molehr/gay002)

Menotti-Raymond M \& O'Brien SJ 2008 The domestic cat, Felis catus, as a model of hereditary and infectious disease. In Sourcebook of Models for Biomedical Research, pp. 221-232.

Nagashima J, Wildt DE, Travis AJ \& Songsasen N 2017 Follicular size and stage and gonadotropin concentration affect alginateencapsulated in vitro growth and survival of pre- and early antral dog follicles. Reproduction, Fertility, and Development 29 262-273. (https:// doi.org/10.1071/RD15004)

Nagashima JB, Wildt DE, Travis AJ \& Songsasen N 2019 Activin promotes growth and antral cavity expansion in the dog ovarian follicle. Theriogenology 129 168-177. (https://doi.org/10.1016/j. theriogenology.2019.02.018)

Orisaka M, Hattori K, Fukuda S, Mizutani T, Miyamoto K, Sato T, Tsang BK, Kotsuji F \& Yoshida Y 2013 Dysregulation of ovarian follicular development in female rat: LH decreases FSH sensitivity during preantral-early antral transition. Endocrinology $\mathbf{1 5 4}$ 2870-2880. (https://doi.org/10.1210/en.2012-2173)

Paradis F, Novak S, Murdoch GK, Dyck MK, Dixon WT \& Foxcroft GR 2009 Temporal regulation of BMP2, BMP6, BMP15, GDF9, BMPR1A, BMPR1B, BMPR2 and TGFBR1 mRNA expression in the oocyte, granulosa and theca cells of developing preovulatory follicles in the pig. Reproduction 138 115-129. (https://doi. org/10.1530/REP-08-0538)

Pfaffl MW 2001 A new mathematical model for relative quantification in real-time RT-PCR. Nucleic Acids Research 29 e45-e45. (https://doi. org/10.1093/nar/29.9.e45)

Ramesh HS, Gupta PS, Nandi S, Manjunatha BM, Kumar VG \& Ravindra JP 2008 Co-culture of buffalo preantral follicles with different somatic cells. Reproduction in Domestic Animals 43 520-524. (https://doi.org/10.1111/j.1439-0531.2007.00946.x)

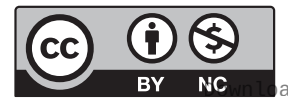

This work is licensed under a Creative Commons Attribution-NonCommercial 4.0 International License. ded from Bioscientifica.com at 04/26/2023 11:26:43AM 
Regan SLP, Knight PG, Yovich JL, Stanger JD, Leung Y, Arfuso F, Almahbobi G \& Dharmarajan A 2018 The effect of ovarian reserve and receptor signalling on granulosa cell apoptosis during human follicle development. Molecular and Cellular Endocrinology 470 219-227. (https://doi.org/10.1016/j. mce.2017.11.002)

Reynaud K, Gicquel C, Thoumire S, Chebrout M, Ficheux C, Bestandji M \& Chastant-Maillard S 2009 Folliculogenesis and morphometry of oocyte and follicle growth in the feline ovary. Reproduction in Domestic Animals 44 174-179. (https://doi. org/10.1111/j.1439-0531.2007.01012.x)

Rojo JL, Linari M, Musse MP \& Peluffo MC 2015 Felis catus ovary as a model to study follicle biology in vitro. Journal of Assisted Reproduction and Genetics 32 1105-1111. (https://doi.org/10.1007/ s10815-015-0511-5)

Ronen-Fuhrmann T, Timberg R, King SR, Hales KH, Hales DB, Stocco DM \& Orly J 1998 Spatio-temporal expression patterns of steroidogenic acute regulatory protein (StAR) during follicular development in the rat ovary. Endocrinology 139 303-315. (https:// doi.org/10.1210/endo.139.1.5694)

Rosen MP, Shen S, Dobson AT, Rinaudo PF, McCulloch CE \& Cedars MI 2008 A quantitative assessment of follicle size on oocyte developmental competence. Fertility and Sterility 90 684-690. (https://doi.org/10.1016/j.fertnstert.2007.02.011)

Roy SK \& Greenwald GS 1985 An enzymatic method for dissociation of intact follicles from the hamster ovary: histological and quantitative aspects. Biology of Reproduction 32 203-215. (https://doi. org/10.1095/biolreprod32.1.203)

Roy SK \& Treacy BJ 1993 Isolation and long-term culture of human preantral follicles. Fertility and Sterility 59 783-790. (https://doi. org/10.1016/S0015-0282(16)55860-9)

Saint-Dizier M, Malandain E, Thoumire S, Remy B \& ChastantMaillard S 2007 Expression of follicle stimulating hormone and luteinizing hormone receptors during follicular growth in the domestic cat ovary. Molecular Reproduction and Development $\mathbf{7 4}$ 989-996. (https://doi.org/10.1002/mrd.20676)

Schmidt VM, Isachenko V, Rappl G, Rahimi G, Hanstein B, Morgenstern B, Mallmann P \& Isachenko E 2018 Comparison of the enzymatic efficiency of Liberase TM and tumor dissociation enzyme: effect on the viability of cells digested from fresh and cryopreserved human ovarian cortex. Reproductive Biology and Endocrinology 16 57. (https://doi.org/10.1186/s12958-018-0374-6)

Short RV 1962 Steroids in the follicular fluid and the corpus luteum of the mare. A 'two-cell type' theory of ovarian steroid synthesis. Journal of Endocrinology 24 59-63. (https://doi.org/10.1677/joe.0.0240059)

Smitz J, Dolmans MM, Donnez J, Fortune JE, Hovatta O, Jewgenow K, Picton HM, Plancha C, Shea LD, Stouffer RL, et al. 2010 Current achievements and future research directions in ovarian tissue culture, in vitro follicle development and transplantation: implications for fertility preservation. Human Reproduction Update 16 395-414. (https://doi.org/10.1093/humupd/ dmp056)

Songsasen N \& Wildt DE 2005 Size of the donor follicle, but not stage of reproductive cycle or seasonality, influences meiotic competency of selected domestic dog oocytes. Molecular Reproduction and Development 72 113-119. (https://doi.org/10.1002/mrd.20330)

Thongkittidilok C, Singh RP, Comizzoli P, Wildt D \& Songsasen N 2018 Insulin promotes preantral follicle growth and antrum formation through temporal expression of genes regulating steroidogenesis and water transport in the cat. Reproduction, Fertility, and Development 30 1369-1379. (https://doi.org/10.1071/RD17454)

Tingen CM, Kiesewetter SE, Jozefik J, Thomas C, Tagler D, Shea L \& Woodruff TK 2011 A macrophage and theca cellenriched stromal cell population influences growth and survival of immature murine follicles in vitro. Reproduction 141 809-820. (https://doi.org/10.1530/REP-10-0483)

Van Wezel IL, Dharmarajan AM, Lavranos TC \& Rodgers RJ 1999 Evidence for alternative pathways of granulosa cell death in healthy and slightly atretic bovine antral follicles. Endocrinology 140 2602-2612. (https://doi.org/10.1210/endo.140.6.6758)

Vanacker J, Camboni A, Dath C, Van Langendonckt A, Dolmans MM, Donnez J \& Amorim CA 2011 Enzymatic isolation of human primordial and primary ovarian follicles with Liberase DH: protocol for application in a clinical setting. Fertility and Sterility 96 379.e373-383.e373. (https://doi.org/10.1016/j. fertnstert.2011.05.075)

Xu M, Banc A, Woodruff TK \& Shea LD 2009 Secondary follicle growth and oocyte maturation by culture in alginate hydrogel following cryopreservation of the ovary or individual follicles. Biotechnology and Bioengineering 103 378-386. (https://doi. org/10.1002/bit.22250)

Yamamoto S, Konishi I, Tsuruta Y, Nanbu K, Mandai M, Kuroda H, Matsushita K, Hamid AA, Yura Y \& Mori T 1997 Expression of vascular endothelial growth factor (VEGF) during folliculogenesis and corpus luteum formation in the human ovary. Gynecological Endocrinology 11 371-381. (https://doi. org/10.3109/09513599709152564)

Young JM \& McNeilly AS 2010 Theca: the forgotten cell of the ovarian follicle. Reproduction 140 489-504. (https://doi.org/10.1530/REP-100094)

Received in final form 9 February 2020

Accepted 23 February 2021

Accepted Manuscript published online 23 February 2021 https://raf.bioscientifica.com

https://doi.org/10.1530/RAF-20-0067 (c) 2021 The authors Published by Bioscientifica Ltd

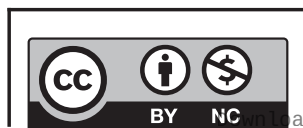

This work is licensed under a Creative Commons Attribution-NonCommercial 4.0 International License. ded from Bioscientifica.com at $04 / 26 / 2023$ 11:26:43AM 